\title{
Grãos Secos de Destilaria na Alimentação de Frangos de Corte
}

\author{
Dry Beans of Distillery to feed Broilers
}

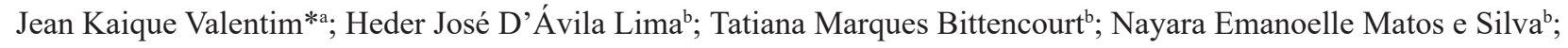
Maria Fernanda de Castro Burbarellia; Rodrigo Garófallo Garciab; Jessica de Carvalho Pantoja ${ }^{\text {a }}$; Deivid Kelly Barbosa ${ }^{\mathrm{a}}$

\author{
anniversidade Federal da Grande Dourados. MS, Brasil \\ bUniversidade Federal do Mato Grosso. MT, Brasil. \\ *E-mail: kaique.tim@hotmail.com
}

\begin{abstract}
Resumo
O uso de coprodutos agroindustriais na alimentação animal promove a diminuição dos custos de produção com insumos básicos como o milho e a soja, evitando os impactos causados pelo descarte desta matéria orgânica no ambiente, além de ser fonte nutricional de qualidade. Dessa forma, os grãos secos de destilaria com solúveis (DDGS) se tornam uma alternativa lucrativa em função de baixo custo, qualidade proteica e apelo sustentável, por ser oriundo da produção de biocombustíveis. Em contrapartida, em decorrência da variabilidade da composição nutricional deste ingrediente, sua adição em dietas avícolas deve ser realizada com cautela, minimizando perdas no desempenho das aves. Dessa forma se buscou avaliar por meio de um artigo de revisão de literatura a utilização de grãos secos de destilaria na dieta de frango de corte. É importante reiterar que os componentes nutricionais podem variar, sendo maior para coprodutos do que para os alimentos convencionais, podendo causar distúrbios nutricionais, se análises frequentes não forem realizadas e se as dietas não forem adequadamente balanceadas, de acordo com a qualidade nutricional do alimento. O DDGS possui grande potencial no uso da alimentação de frango de corte, em função da qualidade nutricional, podendo minimizar custos dentro dessa cadeia.
\end{abstract}

Palavras-chave: Aves de Corte. Biocombustíveis. Coprodutos. DDGS. Milho

\begin{abstract}
The use of agro-industrial co-products in animal feed promotes the reduction of production costs with basic inputs such as corn and soybeans, avoids the impacts caused by the disposal of this organic matter in the environment, besides being a nutritional source of quality. Thus, dry grains of soluble distillery (DDGS) become a profitable alternative due to the low cost, protein quality and sustainable appeal, because it comes from biofuel production. On the other hand, due to the variability of the nutritional composition of this ingredient, its addition in poultry diets should be performed with caution, minimizing losses in the poultries' performance. Thus, it was sought to evaluate through a literature review article the use of dry distillery grains in the broilers' diet. It is important to reiterate that nutritional components may vary, being higher for co-products than for conventional foods, and may cause nutritional disorders, if frequent analyses are not performed and if diets are not properly balanced, according to the food nutritional quality. DDGS has great potential in the use of chicken feeding, due to its nutritional quality, and can minimize costs within this chain.
\end{abstract}

Keywords: Broilers. Biofuels. Co-Products. DDGS. Corn.

\section{Introdução}

Em função do melhoramento das linhagens e o grande investimento em tecnologias na produção de frango de corte, há uma grande eficiência nessa cadeia produtiva. Além disso, outros fatores auxiliam para tais avanços, como o controle das condições sanitárias, aperfeiçoamento pessoal quanto ao manejo das aves e o sistema de produção integrado. Atualmente, a produção de frangos de corte é considerada uma atividade econômica internacionalizada e uniforme, sem fronteiras geográficas e tecnológicas (RODRIGUES et al., 2014).

A busca por combustíveis menos poluentes aumenta o interesse pelo etanol, o Brasil é considerado um dos maiores produtores em escala mundial, sua produção a partir da canade-açúcar é de, aproximadamente, 32,5 bilhões de litros por ano (Agência Nacional de Petróleo (ANP, 2017). Com relação ao milho foram produzidos, no Brasil, cerca de 12 milhões de litros de etanol provenientes de 30.000 toneladas de milho (ANP, 2017). Segundo Salla e Cabello (2010), as vantagens da utilização desse grão na produção de etanol em relação à cana-de-açúcar são: facilidade na armazenagem (no período de entressafra da cana); excesso de produção de milho e baixo custo. Entretanto, o principal problema de seu uso na produção de etanol é a grande variabilidade na composição nutricional e na qualidade desse produto.

Além da produção de etanol, um coproduto está surgindo a partir desta demanda por Biocombustíveis, o "dried distillers grains with solubles" (DDGS) ou grãos secos de destilaria com solúveis de milho, que é obtido após processo de fermentação do amido de milho por leveduras e enzimas (CORTES CUEVAS et al., 2012). Este coproduto é nutritivo e apresenta 
em sua composição um alto teor de proteínas e fibras; que aliado ao baixo custo, é fonte de proteína, aminoácidos, energia, fósforo e outros nutrientes (LUMPKINS et al., 2004).

Na produção animal, o milho e o farelo de soja são os principais insumos utilizados, sendo, respectivamente, fonte de energia e proteína, ambos essenciais para o desempenho do organismo animal. Nesse contexto, o DDGS pode ser uma fonte nutritiva alternativa promissora, e de menor custo na produção animal, incluindo a avicultura de corte.

A alta demanda de insumos na alimentação das aves justifica a utilização de subprodutos da indústria visando minimizar os custos das dietas, visto que esta representa cerca de $70 \%$ dos dispêndios da produção avícola. Em vista do exposto, o objetivo desta revisão é nortear um panorama da utilização de grãos secos de destilaria com solúveis na alimentação de aves de corte.

\section{Desenvolvimento}

\subsection{Metodologia}

Para seleção dos artigos usados nesta revisão foram selecionados das bases de dados: Web of Science, Elsevier, PubMed, Science Direct e Google Scholar. Os termos pesquisados em tais plataformas foram: "Broilers" and "DDGS" and "Nutrition of not ruminants".

Os trabalhos selecionados foram examinados segundo critérios de um teste de relevância, sendo definidos e aplicados os critérios de aceitação e exclusão de artigos não relevantes, utilizando questionário constituído por perguntas que geram uma resposta afirmativa ou negativa que tem relação com o objetivo do estudo. Obtiveram-se as respostas das perguntas do questionário através da leitura do título, resumo e parte dos resultados dos artigos oriundos da busca bibliométrica. Para tal, dois avaliadores responderam "sim" ou "não" as perguntas elaboradas, como:

- A data de publicação compreende o período de 1999 a 2019?

- As palavras chave estão no título e abstract?

- O trabalho contém aspectos nutricionais da utilização de DDG na nutrição de aves de cortes?

Foram inclusos os artigos que apresentaram 100\% de respostas SIM para as perguntas para ambos avaliadores. Os artigos que poderiam ser utilizados foram baixados e avaliados quanto ao critério de avaliação, como: artigos completos; publicados nos últimos 10 anos; contendo descrição completa da metodologia analítica utilizada. Foram escolhidos no total 35 artigos nas três bases indexadas.

\subsection{Milho e soja: as bases da alimentação}

A nutrição é um dos fatores mais importante na produção zootécnica, visto que o desempenho do animal está diretamente ligado aos nutrientes oferecidos. Nutrientes são as substâncias contidas nos ingredientes que compõem as rações (BERTECHINI, 2006). Os nutrientes essenciais são divididos em categorias que incluem as proteínas, minerais, vitaminas, carboidratos, ácidos graxos e água. A alimentação dos animais não ruminantes é constituída basicamente por milho e farelo de soja, que apresentam ótima qualidade nutricional, mas são ingredientes de elevado custo na formulação (ANDRIGUETTO, 2002).

A soja é considerada uma commodity e seu preço é estabelecido pelo mercado internacional, portanto, mesmo o mercado interno apresentando boa oferta deste produto, seu preço varia de acordo com cotações internacionais, não permitindo grandes margens para negociações (SCHONE et al., 2017). Segundo Oliveira et al., (2009), as culturas anuais do milho e soja estão entre as de maior relevância econômica da agricultura brasileira e são os ingredientes mais utilizados na composição de rações para aves. No qual, considerando apenas a produção primária, responde por $37 \%$ da produção nacional de grãos.

Caldarelli et al. (2012) citam que a demanda crescente de milho, tanto interna como externa, reforça o grande potencial do setor. Este insumo é utilizado como fonte de energia na dieta das aves, segundo Rostagno et al. (2017), é composto em média por: $8,21 \%$ de proteína bruta; $2,60 \%$ de fibra bruta; $87,70 \%$ de matéria seca; $69,41 \%$ de extrato não nitrogenado; $1,18 \%$ de matéria mineral; $0,01 \%$ de sódio.

Bittencourt (2018) relata que o farelo de soja é utilizado na ração de aves para suprir a necessidade proteica, além de ser um produto com elevados níveis de aminoácidos digestíveis, como lisina, metionina, treonina e triptofano. Os principais componentes do farelo de soja são: 45,4\% de proteína bruta; $4,86 \%$ de fibra bruta $\% ; 1,95 \%$ de extrato etéreo; $89,6 \%$ de matéria seca; $31,7 \%$ de extrato não nitrogenado; $0,34 \%$ de cálcio; 0,55\% de fósforo (ROSTAGNO et al., 2017).

Para a substituição de qualquer um desses ingredientes base, sem prejuízos na produtividade e lucratividade, é necessário o conhecimento dos coeficientes de digestibilidade dos nutrientes, pela necessidade de se otimizar o uso de matérias-primas de alto custo e, ainda, pelo fato de possibilitar a substituição do milho e do farelo de soja por ingredientes alternativos (SAKOMURA; ROSTAGNO, 2007).

Existe uma grande variedade de alimentos alternativos disponíveis que necessitam de avaliação para serem utilizados nas dietas animais (ROHLOFF, 2015). É necessário determinar a qualidade e o valor nutritivo destes alimentos, e assim verificar se são capazes de substituírem, adequadamente e economicamente, os alimentos convencionais nas dietas dos animais (SCAPINELLO et al., 1996).

$\mathrm{Na}$ avicultura, para diminuir os custos de produção das rações têm sido utilizados diversos recursos, entre esses, a utilização de alimentos alternativos. Na produção do etanol, após o milho ser convertido em álcool por meio da moagem seca, há formação de DDGS. Após o processamento dos grãos = (moagem, maceração, cozimento, hidrólise enzimática, fermentação e destilação), os resíduos que normalmente são 
descartados podem ser aproveitados na alimentação animal (ALVES et al., 2012).

Nesse contexto o DDGS, ingrediente rico em proteína, se torna uma alternativa para a substituição de alimentos convencionais, como o milho, em função de ser competitivo em custo, qualidade nutricional e a facilidade de acesso em determinadas regiões.

\subsection{Produção de etanol e DDGS}

A intensa busca por soluções alternativas para o consumo do petróleo durante os últimos anos se fez em decorrência da preocupação com a poluição ambiental e a emissão de gases de efeito estufa na atmosfera, reforçando cada vez mais a importância da preservação ambiental, e da produção ecológica nos dias atuais. Assim, a produção comercial dos biocombustíveis se torna uma vertente muito visada, para garantir o desenvolvimento sustentável.

Os biocombustíveis em uso comercial no mundo são o etanol e o biodiesel. O etanol pode ser produzido a partir de cereais, ricos em açúcar e amido, como a cana-de-açúcar, o milho, o sorgo, a beterraba, a batata e outros (KHATTAB et al., 2014). Os Estados Unidos é o maior produtor do mundo com a produção de 50 bilhões de litros por ano. Já o Brasil está em segundo lugar no ranking, com a produção de 23 bilhões de litros anuais a partir da cana-de-açúcar (PUPULIN, 2016). Segundo Ribeiro et al. (2010), a produção de etanol está aumentando consideravelmente no mundo todo, a partir da fermentação de açúcares de diversas matérias-primas.

Nos EUA, o etanol era inicialmente o produto mais importante, porém em 2013 o seu coproduto, o DDGS passou a ser relevante, pois a falta de proteína vegetal, em decorrência do baixo estoque de soja, fez a demanda pelo produto crescer até se tonar mais importante economicamente que o etanol.

Em geral, o etanol biocombustível é obtido a partir da quebra do grão em moinhos, após, é adicionada água para fazer uma mistura na qual enzimas carboidrases são introduzidas, ajustando o $\mathrm{pH}$. Essa mistura é preparada em temperaturas que variam entre 90 a $165{ }^{\circ} \mathrm{C}$, removendo bactérias produtoras de ácido lático, depois é realizado o arrefecimento e adicionado enzimas (SCHONE 2017). Dessa forma, a glicose é fermentada em etanol e dióxido de carbono e o etanol é retirado por meio da destilação e uso de peneiras moleculares. Posteriormente, todo o produto é centrifugado (para separar os grãos úmidos) da vinhaça fina (GRAINS COUNCIL EUA, 2012).

O solúvel ou xarope é produzido a partir da vinhaça fina por evaporação e condensação. E por fim, o DDGS é produzido por adição de todos os solúveis aos grãos úmidos, seguido por secagem a temperatura entre 127 e $621^{\circ} \mathrm{C}$ (BREGENDAHL, 2008), finalizando assim seu processo de produção (Figura 1).
Figura 1 - Esquema do processamento do etanol de milho

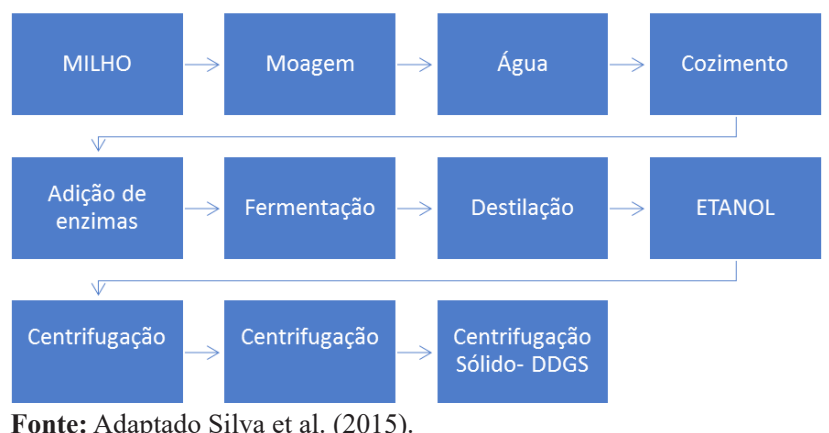

Fonte: Adaptado Silva et al. (2015).

O processo consiste em converter os amidos e açúcares dos cereais em etanol, sendo que as percentagens remanescentes dos nutrientes são proporcionalmente concentradas, o que maximiza o seu teor proteico (DE BLAS et al., 2010).

O DDGS pode apresentar diferenças na sua composição, em função da variabilidade da matéria-prima. Podendo variar, inclusive, dentro de uma mesma usina entre lotes e ainda de usina para usina (CREMONEZ et al., 2015). As principais causas destas variações são: a qualidade da matéria-prima, diferentes processos para obtenção do etanol, variações na proporção de mistura dos componentes na produção do DDGS, tempo e temperatura de secagem (SHURSON; ALGHAMDI, 2008). É um alimento rico em fibra, proteína, aminoácidos, fósforo e energia (LUMPKINS et al., 2004).

Segundo Lim et al. (2011), o DDGS de milho obtido por meio do processamento convencional apresenta, em média: matéria seca (MS) (89\%), proteína bruta (PB) (26 a 32\%), fibra em detergente neutro (FDN) (34\%), extrato etéreo (EE) (8 a 12\%); e nutrientes digestíveis totais (NDT) (81\%). Quanto às fibras, o DDGS possui teor mais elevado de fibra em detergente neutro do que em detergente ácido. Segundo Bittencourt (2018), a composição de DDGS é: PB (42,73\%), FB (18,32\%), MM (1,87\%), MS (89\%), ENN (47,73\%), cálcio $(0,13 \%)$, fósforo (0,53\%). Já Belyea et al. (2004) encontraram valores médios de PB (31,4\%), EE (12\%) e FDA (16,8\%).

Spiehs et al. (2002) avaliaram o teor de nutrientes do DDGS originários de novas usinas de etanol e concluíram que o conteúdo médio de proteína bruta foi de $30,2 \%$, gordura bruta - $10,9 \%$, fibra bruta $-8,8 \%$, cinza $-5,8 \%$, nitrogênio extrativos livres - 45,5\%, - 16,2\%, NDF - 42,1\%, lys - 0,85\%, met $0,55 \%$, Ca $-0,06 \%$ e P - $0,89 \%$, os autores relatam que a alta variabilidade entre as fontes foi encontrada, especialmente, para lisina e minerais.

O conteúdo de alguns nutrientes no DDGS difere não apenas entre plantas de produção, mas também entre anos de produção, composição original do grão, eficiência da fermentação do amido durante a produção de etanol escala de fermentação, diferentes quantidades de solúveis adicionados e outros procedimentos como a secagem (temperatura e duração) (LEWANDROWSKI et al., 2019).

O amido, em sua maioria, é utilizado na produção do etanol, 
o DDGS, portanto, fica mais concentrado e assim possui uma maior quantidade de carboidratos fibrosos, quando comparado à quantidade fibrosa dos grãos que lhes originam (STEIN; SHURSON, 2009), se caracterizando como coproduto de alta concentração de hemicelulose (SILVA, 2015).

\subsection{Uso de DDGS aplicado a nutrição de frangos de corte}

Segundo Schone et al. (2017), o emprego do DDGS na alimentação de não ruminantes é uma prática recente, uma vez que o alto conteúdo fibroso limitou sua utilização apenas para ruminantes. Alguns estudos têm sido desenvolvidos visando determinar níveis e alternativas de inclusão do DDGS na alimentação de frangos de corte, sendo esse alimento reconhecidamente uma fonte de energia, proteína, vitaminas e minerais (WANG et al., 2008).

É preciso ressaltar que a variabilidade dos componentes nutricionais é maior para coprodutos do que para os alimentos convencionais, podendo causar distúrbios nutricionais, se análises frequentes não forem realizadas e se as dietas não forem adequadamente balanceadas, de acordo com a qualidade nutricional do alimento.

Dessa forma, são necessários maiores esclarecimentos sobre os efeitos diretos decorrentes da utilização de diferentes tipos de resíduos agroindustriais na alimentação animal, principalmente, quanto à qualidade do produto final e seus derivados, considerando-se o desempenho, composição química, propriedades físico-químicas e qualidade de produtos cárneos (BELYEA et al., 1989).

A maior dúvida é quanto a variação do conteúdo dos aminoácidos (SILVA et al., 2015). Mesmo quando os teores de proteína são elevados, o DDGS possui problemas com os teores de lisina, metionina e triptofano, que são encontrados em baixas quantidades, o que muitas vezes faz com que esses aminoácidos necessitem ser adicionados, em suas formas industriais, nas dietas dos animais, visando melhorar seu desempenho (ROHLOFF, 2015).

Świątkiewicz e Koreleski (2008) discorrem que em decorrência da alta variabilidade e baixa disponibilidade de alguns nutrientes, o DDGS tem sido utilizado em dietas de aves a baixas taxas de inclusão (aproximadamente 5\%). Por causa de maior qualidade de nutrientes, relacionada a sua exposição e à secagem, ao aquecimento e às preparações,

O amido representa cerca de 65 a $68 \%$ do grão de milho, destes, $90 \%$ é utilizado na produção do etanol, o DDGS, portanto fica mais concentrado, apresentando maiores concentrações de lipídios, minerais, proteínas e carboidratos fibrosos quando comparado aos grãos que lhes originam, em que se atingem valores de FDA superiores a $10 \%$ e FDN acima de 30\% (STEIN; SHURSON, 2009).

Segundo Rohloff (2015), o fator fibra é muito importante quando se trata de animais não ruminantes, tendo em vista que estes não possuem a capacidade de digestão de fibras, portanto, quanto maior o teor de fibra presente nos alimentos, maior a dificuldade de utilização nas dietas para animais, o que pode prejudicar o desempenho animal. Isso ocorre porque a fibra em alta concentração diminui a energia metabolizável das rações e o aproveitamento dos nutrientes e, consequentemente, acarreta redução na taxa de crescimento e piora na eficiência alimentar (FURLAN et al., 2001).

Outro ponto a ser discutido é com relação ao incremento calórico da fibra existente neste coproduto. Incremento calórico pode ser definido como a energia produzida nos processos de digestão, absorção e metabolismo dos nutrientes (GOMIDE et al., 2011). Segundo Musharaf e Latshaw (1999), em comparação à gordura e ao amido, a proteína e a fibra proporcionam maior incremento calórico durante o metabolismo, o que pode prejudicar o desempenho animal.

$\mathrm{Na}$ alimentação de frangos de corte, alguns experimentos foram conduzidos visando maximizar o desempenho e diminuir os custos produtivos na alimentação destes animais. Lumpkins et al., (2004) avaliaram diferentes níveis de inclusão de DDGS, $0,6,12$, ou $18 \%$, na dieta de frangos de corte e não observaram efeito no ganho em peso, na conversão alimentar e no rendimento de carcaça para os diferentes níveis na fase total de produção, concluindo que este coproduto pode ser utilizado em até $18 \%$ nas dietas sem prejudicar o desempenho das aves.

Salim et al. (2010) relataram que até 25\% de DDGS seria o ideal para ganho de peso e ingestão alimentar. Porém, Schone et al. (2017) relatam que níveis de 5 a $20 \%$ de inclusão de DDGS nas rações promovem queda no desempenho e no rendimento de carcaça de frangos de corte, machos e fêmeas, além de maior deposição de gordura abdominal nas fêmeas, este fato foi explicado em função de características do produto utilizado no experimento, sendo mais fibroso e menos proteico, justificando assim a queda no desempenho.

Já Cortes Cuevas et al. (2012) observaram que a adição de $7 \%$ de DDGS em dietas à base de sorgo para frangos de corte não afetou o desempenho produtivo, o rendimento de carcaça, peito e coxas. Em trabalho conduzido por Wang et al. (2008), a inclusão de até $20 \%$ de DDGS em dietas para frangos de corte não afetou o ganho de peso e a conversão alimentar, enquanto a inclusão de até $25 \%$ de DDGS aumentou o consumo de ração em 4\% e diminuiu o rendimento de carcaça em $2 \%$.

Loar et al. (2009) determinaram valor máximo de inclusão de $8 \%$ na dieta para frangos de corte que não houvesse prejuízo no rendimento de carcaça e ganho de peso. Wuhaan et al. (2010), trabalhando com até 20\% de DDGS na dieta de frangos, concluíram que a utilização não afetava o desempenho. Schilling et al. (2010) verificaram que a inclusão de até $12 \%$ não prejudica o desempenho, porém a carne das aves submetidas à inclusão de mais de $12 \%$ apresenta maior índice de oxidação, em decorrência do elevado teor lipídico do DDGS.

Segundo Świątkiewicz e Koreleski (2008), a cor do DDGS também pode variar de acordo com o tempo de aquecimento que cada usina utiliza, os escores de cor variam de muito leve a escores muito escuros e odor variaram de normal a queimado 
(esfumaçado), a cor escura e odor queimado provavelmente é causado por superaquecimento durante o processo de secagem. Este superaquecimento que gera um DDGS mais escuro pode causar uma concentração mais baixa de lisina, além de diminuir a palatabilidade do produto afetando o desempenho animal.

Batal e Dale (2006) observaram diferenças $(\mathrm{p}<0,005)$ na digestibilidade dos aminoácidos verdadeiros entre DDGS com padrão de cores diferentes, e concluíram que amostras amarelas e mais leves eram caracterizadas por maiores níveis de aminoácidos totais e digestíveis, especialmente lisina. Amostras mais escuras de DDGS podem ter menor conteúdo aminoacídico devido ao aquecimento excessivo que causa a reação de Maillard diminuindo os teores de aminoácidos, principalmente a lisina.

Ergul et al. (2003) observaram uma correlação positiva significativa entre lisina, digestibilidade e a luminosidade ( $\mathrm{L}$ *) e cor amarelo $\left(b^{*}\right)$ do DDGS, sugerindo que a análise de cores pode ser um método rápido e confiável de estimar o teor de aminoácidos do coproduto.

O DDGS é um coproduto que se enquadra na categoria de alimento proteico e energético, que pode ser utilizado em dietas de frangos de corte em todo o ciclo produtivo em determinadas inclusões, porém atenção deve ser dada para a composição nutricional, principalmente, em relação ao teor de aminoácidos e minerais, que varia em relação ao processo de fabricação de cada usina, por isso, este alimento necessita de análises bromatológicas e aminoacídicas antes de ser adicionado às rações.

\section{Conclusão}

A utilização do DDGS em dietas de aves ainda deve ser utilizada com precaução, porém este ingrediente apresenta grande potencial de utilização na formulação de rações, em função de sua qualidade nutricional, podendo diminuir os custos com a alimentação de frangos de corte.

\section{Referências}

ALVES, J. O. et al. Síntese de nano materiais de carbono a partir de resíduos de milho (DDGS). Quím. Nova, v.35, n.8, p.1534$1537,2012$.

ANDRIGUETTO, J.M.; PERLY, L. Nutrição animal: bases e fundamentos. Barueri: NBL, 2002.

ANP - Agência Nacional do Petróleo, Gás Natural. 2017. Disponível em: http://www.anp.gov.br. Acesso em: 12 jun. 2020.

BATAL, A.B.; DALE, N.M. True metabolizable energy and amino acid digestibility of distillers dried grains with solubles. $J$. Appl. Poultry Res., v.15, n.1, p.89-93, 2006.

BELYEA, R.L.; RAUSCH, K.D.; TUMBLESON, M.E. Composition of corn and distillers dried grains with solubles from dry grind ethanol processing. Bioresource Technol., v.94, n.3, p.293-298, 2004. doi: 10.1016/j.biortech.2004.01.001

BERTECHINI, A.G. Nutrição de monogástricos. Lavras: UFLA, 2006.
BITTENCOURT, T.M. Níveis de grãos secos de destilaria de milho na alimentação de aves poedeiras. Diamantina: Universidade Federal dos Vales do Jequitinhonha e Mucuri, 2018.

BREGENDAHL, K. Use of distillers co-products in diets fed to poultry. Using distillers grains in the us and international livestock and poultry industries. MATRIC Iowa State University, Ames, p.99-133, 2008.

CALDARELLI, C.E.; BACCHI, M.R.P. Fatores de influência no preço do milho no Brasil. Nova Econ., v.22, n.1, p.141-164, 2012. doi: $10.1590 / \mathrm{S} 0103-63512012000100005$

CORTES CUEVAS, A. et al. El uso de granos secos de destilería con solubles (DDGS) en dietas sorgo-soya para pollos de engorda y gallinas de postura. Rev. Mexicana Cienc. Pecuarias, v.3, n.3, p.331-341, 2012.

CREMONEZ, P.A. et al. Codigestão de água residual de suinocultura e vinhaça sob diferentes condições térmicas. Rev. Ciênc. Agrárias, v.38, n.1, p.103-110, 2015.

DE BLAS, C.; MATEOS, C.C. Nutrition of the rabbit. Cambrige University Press, 2010.

ERGUL, T. et al. Amino acid digestibility in corn distillers dried grains with solubles. Poulry. Scie., v. 82, n. Suppl 1, p.70, 2003.

FURLAN, A.C. et al. Utilização do farelo de girassol na alimentação de frangos de corte. Rev. Bras. Zootec., v.30, n.1, p.158-164, 2001. doi: 10.1590/S1516-35982001000100023

GOMIDE, E.M. et al. Rações com níveis reduzidos de proteína bruta, cálcio e fósforo com fitase e aminoácidos para frangos de corte. Rev. Bras. Zootec., v.40, n.11, p.2405-2414, 2011.

GRAINS COUNCIL, US. A guide to distiller's dried grains with solubles (DDGS). US Grains Counc. 2012.

KHATTAB, W. et al. Dried distiller's grains with solubles (DDGS) inclusion and allzyme ssf® supplementation in growingfinishing rabbit diets: impact on growth performance. Benha Vet. Med. J., v.26, n.1, p.171-177.

LEWANDROWSKI, J. et al. The greenhouse gas benefits of corn ethanol-assessing recent evidence. Biofuels, v.10, p.1-15, 2019. doi: 10.1080/17597269.2018.1546488

LIM, C.; LI, E.; KLESIUS, P.H. Distiller's dried grains with solubles as an alternative protein source in diets of tilapia. Rev. Aquaculture, v.3, n.4, p.172-178, 2011. doi: 10.1111/j.17535131.2011.01054.x

LOAR, R E. et al. Effects of elutriation and sieving processing (Elusieve) of distillers dried grains with solubles on the performance and carcass characteristics of male broilers. J. Appl. Poultry Res., v.18, n.3, p.494-500, 2009.

LUMPKINS, B.S.; BATAL, A.B.; DALE, N. M. Evaluation of distillers dried grains with solubles as a feed ingredient for broilers. Poultry Scie., v.83, n.11, p.1891-1896, 2004.

MUSHARAF, N.A.; LATSHAW, J.D. Heat increment as affected by protein and amino acid nutrition. World's Poultry Scie. J., v.55, n.3, p.233-240, 1999. doi: 10.1079/WPS19990017P

OLIVEIRA DIASI, V.; BENEDETTI, A.S.A.U.; BONOTTOI, B.G.J. Distribuição de sementes de milho e soja em função da velocidade e densidade de semeadura. Ciênc. Rural, v.39, n.6, p.1721-1728, 2009.

PUPULIN, C. Canal Jornal da Bioenergia, 2016. Disponível em: http://www.canalbioenergia.com.br/etanol-de-cana-e-de-milhodiferencas-importantes-mas-convergencia-parece-ser-umatendencia/. Acesso em: 18 out. 2019

RIBEIRO, A.M.L. et al. Suplementação de vitaminas e minerais 
orgânicos e sua ação sobre a imunocompetência de frangos de corte submetidos a estresse por calor. Rev. Bras. Zootec., v.37, n.4, p.636-644, 2008. doi: 10.1590/S1516-35982008000400008

RODRIGUES, W.O.P. Evolução da avicultura de corte no brasil. Enciclopédia Biosfera, Centro Científico Conhecer - Goiânia, v.10, n.18, p. 2014.

ROHLOFF JUNIOR, N. Coproduto seco de destilaria com solúveis de milho na alimentação de coelhos. Marechal Cândido Rondon: Universidade Estadual do Oeste do Paraná, 2015.

ROSTAGNO, H.S. et al. Composição de alimentos e exigências nutricionais. Tabelas Brasileiras Aves Suínos, v. 2, 2005.

SAKOMURA, N.K.; ROSTAGNO, H.S. Métodos de pesquisa em nutrição de monogástricos. Jaboticabal: Funep, 2007.

SALIM, H.M.; KRUK, Z.A.; LEE, B.D. Nutritive value of corn distillers dried grains with solubles as an ingredient of poultry diets: a review. World's Poultry Scie. J., v.66, n.3, p.411-432, 2010. 10.1017/S0043933910000504

SALLA, D.A.; CABELLO, C. Análise energética de sistemas de produção de etanol de mandioca, cana-de-açúcar e milho. Rev. Energia Agricultura, v.25, n.2, p.32-53, 2010.

SCAPINELLO, C. et al. Utilização da levedura de recuperação (Saccharomyces sp.), seca pelo método spray-dry para coelhos em crescimento. Rev. Unimar, v.18, n.3, p.587-598, 1996.

SCHILLING, M.W. et al. Dietary inclusion level effects of distillers dried grains with solubles on broiler meat quality. Poultry Scie., v.89, n.4, p.752-760, 2010.

SCHONE, R.A. et al. Resíduo seco de destilaria com solúveis (DDGS) na alimentação de frangos de corte (22-42 dias). Rev Ciênc. Agronômica, v.48, n.3, p.548-557, 2017. doi:

\section{$10.5935 / 1806-6690.20170064$}

SHURSON, J.; ALHAMDI, A.S. Quality and new technologies to create corn co-products from ethanol production. Using Distillers Grains in the US and International. Livestock Poultry Ind., p.231256, 2008.

SILVA, J. R. Resíduo seco de destilaria contendo solúveis (DDGS), com e sem xilanase, na alimentação de cães. Curitiba: Universidade Federal do Paraná, 2015. Curitiba.

SILVA, J.R.; NETTO, D.P.; SCUSSEL, V.M. Grãos secos de destilaria com solúveis, aplicação em alimentos e segurança-uma revisão. Pubvet, v.10, p.190-270, 2015.

SPIEHS, M.J.; WHITNEY, M.H.; SHURSON, G.C. Nutrient database for distiller's dried grains with solubles produced from new ethanol plants in Minnesota and South Dakota. J. Anim. Sci., v.80, n.10, p.2639-2645, 2002. doi: 10.1093/ansci/80.10.2639

STEIN, H.H.; SHURSON, G.C. Board-invited review: the use and application of distillers dried grains with solubles in swine diets. J. Animal Scie., v.87, n.4, p.1292-1303, 2009. doi: 10.2527/ jas.2008-1290

ŚWIĄTKIEWICZ, S.; KORELESKI, J. The use of distillers dried grains with solubles (DDGS) in poultry nutrition. World's Poultry Scie. J., v.64, n.2, p.257-266, 2008. doi: 10.1017/ S0043933908000044

WANG, Z. et al. Evaluation of high levels of distillers dried grains with solubles (DDGS) in broiler diets. Int. J. Poultry Scie., v.7, n.10, p.990-99, 2008.

WU-HAAN, W. et al. The use of distillers dried grains plus solubles as a feed ingredient on air emissions and performance from laying hens. Poultry Scie., v.89, n.7, p.1355-1359, 2010. 